\title{
Viscoelastic properties of low-shrinking composite resins compared to packable composite resins
}

\author{
Dimitris PAPADOGIANNIS ${ }^{1}$, Kosmas TOLIDIS ${ }^{2}$, Roderic LAKES $^{3}$ and Yiannis PAPADOGIANNIS ${ }^{2}$ \\ ${ }^{1}$ Department of Biomaterials, School of Dentistry, University of Athens, Greece \\ ${ }^{2}$ Department of Operative Dentistry, School of Dentistry, Aristotle University of Thessaloniki, Greece \\ ${ }^{3}$ Department of Engineering Physics, Engineering Mechanics Program and Department of Biomedical Engineering, Materials Science Program and \\ Rheology Research Center, University of Wisconsin, Madison, WI, USA \\ Corresponding author, Dimitris PAPADOGIANNIS; E-mail: deminho@gmail.com
}

\begin{abstract}
The aim of this study was to evaluate the viscoelastic properties of novel low-shrinking composites and compare them to those of packable composites. Six materials were tested: Clearfil Majesty Posterior (CM), ELS Extra Low Shrinkage (EL), Filtek P60 (FP), Filtek Silorane (FS), Prodigy (PR) and Surefil (SU). Static and dynamic testing was performed and materials were tested dry and wet at different temperatures $\left(21^{\circ} \mathrm{C}\right.$ to $\left.50^{\circ} \mathrm{C}\right)$. Shear and flexural modulus, loss tangent, dynamic viscosity, Poisson's ratio and creep recovery were calculated among others. Significant differences were found both between the two groups and between materials belonging to the same group. CM presented the highest shear and flexural modulus and EL the lowest. All materials were softened by an increase of temperature, while FS was the least affected by water and PR showed to be the most susceptible. Different approaches used to overcome polymerization shrinkage lead to materials with different properties.
\end{abstract}

Keywords: Polymerization shrinkage, Elastic modulus, Creep, Viscosity

\section{INTRODUCTION}

Although composite resins were introduced as aesthetic materials for anterior restorations, their use was quickly extended to posterior teeth. The increased mechanical requirements in stress bearing posterior cavities along with the early composites' inadequate resistance to wear ${ }^{1)}$ resulted into frequent failures. The need for composites with improved mechanical properties led to changes in their composition with the construction of restoratives named as packable composites that were recommended as a substitute of amalgam ${ }^{2}$.

As composites perform under masticatory forces, mechanical properties are critical for their longevity and parameters as the modulus of elasticity can be indicative of their performance. Both static and dynamic tests have been used for the determination of the mechanical properties of composite resins in prior studies. Tests such as creep focus on the response to the static component of forces, relating to the parts of the restored tooth that may undergo progressive motion. By contrast, dynamic tests reveal the response to sinusoidal components of load and reveal energy dissipation as well as the response to impacts.

Despite the evolution of composite resins and the improvement of the adhesive systems, composite restorations still present some drawbacks. One of the major disadvantages is that their setting is accompanied by polymerization shrinkage, which consequently leads to the generation of polymerization stress and can be the cause of clinical failure. Depending on the bond strength between tooth structure and composite, imperfect margins around the restoration form and can lead to post-operative sensitivity, secondary caries and marginal discoloration that can reduce the longevity of the restoration ${ }^{3)}$. Moreover, the stresses are transferred into the tooth structure and can cause micro-fractures and cusp movement ${ }^{4}$.

Many efforts have been made in order to reduce the volumetric shrinkage of composite resins, with different approaches being used ${ }^{5,6}$. New materials are being introduced claiming to present low polymerization shrinkage and being suitable for use posterior teeth, where setting stresses can be critical for the survival of the restoration.

The aim of this study was to evaluate the viscoelastic properties and resistance to creep deformation of novel composites with low polymerization shrinkage and compare them to those of traditional packable composite resins designed for posterior restorations. The null hypothesis was that no significant differences would be found among the newer low-shrinking composites and the packable, exhibiting similar viscoelastic properties.

\section{MATERIALS AND METHODS}

The composite resins used in the study are listed in Table 1. All materials were of A2 shade. Three of the materials (FP, PR, SU) are packable composite resins, while the other three (CM, EL, FS) are materials recently introduced as possessing low volumetric shrinkage.

The uncured composites were inserted into glass capillary tubes $(\mathrm{d}=0.85 \mathrm{~mm}, \mathrm{l}=18 \mathrm{~mm})$ and were light-cured $\left(40 \mathrm{~s}, 600 \mathrm{~mW} / \mathrm{cm}^{2}\right.$ Coltolux 4 light, Coltene Whaledent, Konstanz, Germany). The specimens were mounted, using a jig for centering, between a Plexiglas disc $(0.5 \mathrm{~mm}$ thick) and a rod with use of self-curing composite. 
Table 1 The materials used in the study

\begin{tabular}{|c|c|c|}
\hline Material & Composition & Manufacturer \\
\hline Clearfil Majesty Posterior (CM) & $\begin{array}{l}\text { Resin: Bis-GMA, TEGDMA, ArDMA } \\
\text { Filler: } 82 \text { vol } \% \text { - } 92 \text { wt } \%\end{array}$ & Kuraray, Okayama, Japan \\
\hline ELS Extra-Low Shrinkage (EL) & $\begin{array}{l}\text { Resin: Bis-GMA, Bis-EMA } \\
\text { Filler: } 75 \text { wt } \%\end{array}$ & Saremco, St Gallen, Switzerland \\
\hline Filtek P60 (FP) & $\begin{array}{l}\text { Resin: Bis-GMA, UDMA, Bis-EMA } \\
\text { Filler: } 61 \text { vol } \% \text { - } 83 \text { vol } \%\end{array}$ & 3M Espe, Seefeld, Germany \\
\hline Filtek Silorane (FS) & $\begin{array}{l}\text { Resin: Polysilorane } \\
\text { Filler: } 53 \text { vol\% - } 73 \text { wt } \%\end{array}$ & 3M Espe, Seefeld, Germany \\
\hline Prodigy (PR) & $\begin{array}{l}\text { Resin: Bis-GMA, TEGDMA, } \\
\text { Filler: } 60 \text { vol } \% \text { - } 79 \text { wt } \%\end{array}$ & Kerr, Orange, CA, USA \\
\hline Surefil (SU) & $\begin{array}{l}\text { Resin: Bis-GMA, UDMA } \\
\text { Filler: } 60 \text { vol } \% \text { - } 82 \text { wt } \%\end{array}$ & Dentsply DeTrey, Konstanz, Germany \\
\hline
\end{tabular}

ArDMA: Aromatic dimethacrylates, Bis-EMA: Bisphenol A ethoxylated methacrylate, Bis-GMA: Bisphenol A glycidil methacrylate, TEGDMA: Tetraethyleneglycol dimethacrylate, UDMA: Urethane dimethacrylate

The apparatus used in this study (Figure 1) can perform torsion and bending tests of cylindrical specimens and has been used before for various dental materials ${ }^{7,8)}$. Torque is generated by a permanent, highintensity, Sm-Co magnet which is attached to the end of the specimen and placed at the center of a Helmholtz coil. The magnet $\left(\mathrm{M}=2.75 \times 10^{-3} \mathrm{Nm} / \mathrm{A}\right)$ is able to produce torque on the specimen, controlled by the current in the coil. A thin mirror $(\mathrm{d}=5 \mathrm{~mm})$ was cemented onto the magnet in order to reflect the laser beam of a low power $\mathrm{He}-\mathrm{Ne}$ laser on a calibrated chart at a distance $\mathrm{D}=944$ $\mathrm{cm}$.

The distribution of shear strain, $\gamma$, in a circular cylinder under torsion is $\gamma=r \varphi / L$, where $r$ is the radial distance from the centerline and $L$ is the length of the cylinder. The distribution of shear stress $\sigma$ depends on the material properties of the specimen and in the case of linearly elastic or linearly viscoelastic materials it is given by $\sigma=M R /\left(\pi R^{4} / 2\right)$, where $R$ is the specimen radius and $M$ is the torque. When small stresses are being used, the specimens are linearly viscoelastic and torsion results can be easily interpreted.

\section{Static and dynamic viscoelastic measurements}

The materials were tested under four different conditions (at $21^{\circ} \mathrm{C}$ dry and at $21^{\circ} \mathrm{C}, 37^{\circ} \mathrm{C}$ and $50^{\circ} \mathrm{C}$ wet). The specimens tested wet were stored in a beaker with distilled water for $24 \mathrm{~h}$.

For the determination of the static shear moduli of the materials a constant torque was rapidly applied to the specimen and maintained for $3 \mathrm{~h}$. The angular displacement was recorded and the torque was then rapidly released. The shear modulus $G=\sigma / \gamma$ was calculated from the equation $G=2 M L / \pi R^{4} \varphi$. The shear stress and shear modulus at $10 \mathrm{~s}$ reflect the short-time viscoelastic response of the material. Compliance $J$ is the

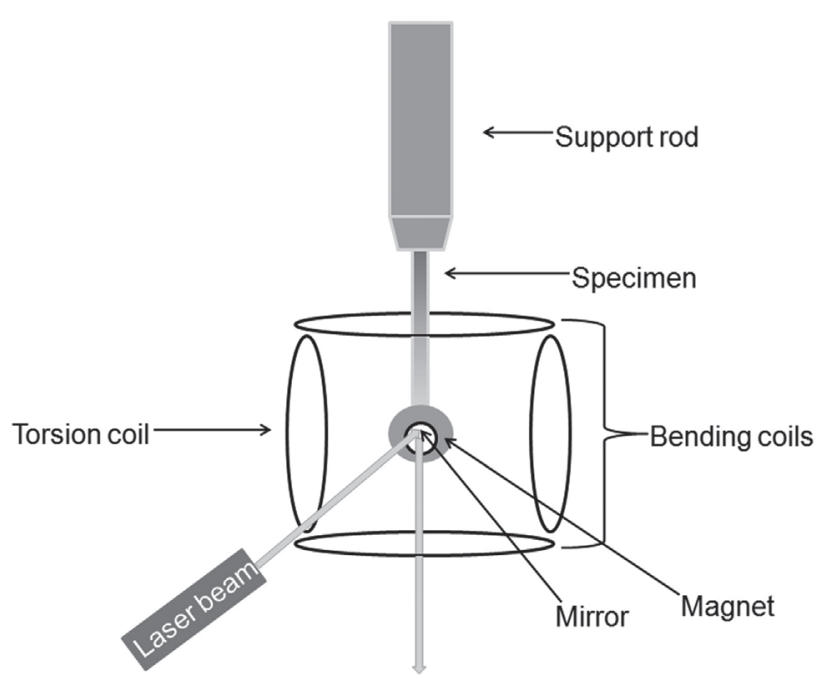

Fig. 1 Apparatus used in the study.

reciprocal of the shear modulus. The time dependent creep response was recorded as described below.

Young's modulus of elasticity $E$ was obtained by repeating the experiment after the coil was rotated for $90^{\circ}$ in order to achieve bending. Again, a constant torque was applied to the specimen for $10 \mathrm{~s}$ and then "instantaneously" released. The distribution of flexural strain $\varepsilon$, in a circular cylinder in bending is: $\varepsilon=r \varphi / L$. Young's modulus $E=\sigma / \varepsilon$ was calculated from the equation: $E=64 \mathrm{ML} / \pi d^{4} \varphi$. Poisson's ratio $v$ was calculated from: $E=2 G(1+v)$, using the values of $G$ and $E$ calculated in static measurements.

In dynamic mechanical analysis, when steady state is reached and viscoelastic behavior is linear, both stress 
and strain vary sinusoidally and strain lags behind the stress. The storage modulus $G_{1}$ (the real part of the complex modulus $G^{*}$ ) is in phase with strain, whereas the loss modulus $G_{2}$ (the imaginary part of the complex modulus $G^{*}$ ) is $90^{\circ}$ out of phase with the strain and is related to the dissipation of energy. In most cases of stiff materials $G_{2}$ is small compared to $G_{1}$ and therefore $G^{*}$ is approximately equal to $G_{1}$ and is loosely referred as modulus $G$. The ratio of the imaginary part to the real part of the complex modulus $G^{*}$ is referred to as internal damping or loss tangent $(\tan \delta)$. The angle $\delta$ is the phase angle between stress and strain sinusoids. The loss tangent is proportional to the energy loss per cycle within the framework of linear viscoelasticity.

In the present study frequencies that ranged from 1 to $100 \mathrm{~Hz}$ were used for the dynamic torsional vibration of the specimens tested. Sinusoidal torque was applied via a function generator connected to the Helmholtz coil. Frequency was varied to tune through resonance. The displacement of amplitude was measured for on the chart for each frequency. The viscoelastic parameters were calculated by using the resonance frequency $v_{0}$, which corresponds to the peak amplitude and the resonance full width $\Delta v$, which is the difference between the two frequencies at which the amplitude is half of the maximum. The loss tangent is calculated from the following equation: $\tan \delta=\left(\frac{1}{\sqrt{3}}\right) \frac{\Delta v}{v_{0}}$ and the storage modulus from: $v_{0}=\left(\frac{1}{2 \pi}\right) \sqrt{\frac{G_{1} \pi r^{4}}{2 L I}}$ where $L$ is the length of the specimen, $r$ the radius of the specimen and $I$ is the moment of inertia of the magnet which was measured to be $4.4 \times 10^{-7} \mathrm{~kg} \cdot \mathrm{m}^{2}$. Dynamic viscosity $n^{*}$ was calculated from: $n^{*}=\left(\frac{1}{\omega_{0}}\right) \sqrt{G_{1}^{2}+G_{2}^{2}}$ where $\omega_{0}=2 \pi v_{0}$.

\section{Creep measurements}

The experiment consisted of applying a constant torque and recording the angular displacement of the specimen for duration of $3 \mathrm{~h}$. The stress was then released and the recovery was recorded for $50 \mathrm{~h}$. The specimens were tested under four different torques generated by increasing the electrical current producing different initial stresses ranging from $1.14 \mathrm{MPa}$ to $3.42 \mathrm{MPa}$. However for materials CM and SU the displacement at the lowest stresses was too small to accurately measure. These were also tested at $4.56 \mathrm{MPa}$ and $5.7 \mathrm{MPa}$ for comparison purposes.

\section{Statistical analysis}

Statistical analysis for the static and dynamic measurements among different materials were performed by two-way analysis of variance (ANOVA) accompanied by Bonferroni post-tests $(\alpha=0.05)$. The independent parameters were the materials and the testing condition, while in creep measurements the parameters were the materials and torque.

\section{RESULTS}

Mean values of $G$ and $E$ under static testing and the calculated $v$ that derives from those values are shown in Table 2, while mean values of $G_{1}, G_{2}, n^{*}$ and $\tan \delta$ under dynamic testing are shown in Table 3 . The mean values of $\gamma_{0}, \% \gamma_{\tau} / \gamma_{0}, \%$ recovery and initial $G$ in $10 \mathrm{~s}$ are shown in Table 4 . The effect of water and temperature increase in $G_{1}, n^{*}, E$ and $\tan \delta$ is shown in Figure 2, while creep and compliance curves are shown in Figure 3 and Figure 4.

Based on the results of this study, the null hypothesis has to be rejected. Material CM presented the highest values for $G$ and $E$ both in static and dynamic testing and under all conditions, while EL had the lowest modulus. CM also presented the highest dynamic viscosity, with materials EL and PR showing the lowest. All materials presented a decrease in their moduli when tested wet, with the exception of FS under dynamic testing, while the increase of temperature from $21^{\circ} \mathrm{C}$ to $50^{\circ} \mathrm{C}$ also led to a decrease of their moduli.

All materials showed typical linear viscoelastic behavior under creep exhibiting elastic strain, viscoelastic and viscous flow and the phase of recovery;

Table 2 Results of shear modulus G, Young's Modulus E and Poisson's ratio $v$ under static testing (mean and S.D.)

\begin{tabular}{|c|c|c|c|c|c|c|c|}
\hline & & $\mathrm{CM}$ & EL & FP & FS & PR & SU \\
\hline \multirow{4}{*}{$\begin{array}{l}\text { Shear } \\
\text { modulus } G \\
(G P a)\end{array}$} & Dry $21^{\circ} \mathrm{C}$ & $8.89(.08)$ & $5.24(.14)^{\mathrm{a}}$ & $7.49(.07)$ & $5.34(.06)^{\mathrm{a}}$ & $5.57(.13)$ & $7.24(.07)$ \\
\hline & Wet $21^{\circ} \mathrm{C}$ & $8.43(.12)$ & $4.82(.18)$ & $6.63(.14)^{\mathrm{b}}$ & $5.15(.1)$ & $4.55(.15)$ & $6.64(.12)^{\mathrm{b}}$ \\
\hline & Wet $37^{\circ} \mathrm{C}$ & $7.05(.11)$ & $3.9(.08)$ & $6.24(.23)^{\mathrm{c}}$ & $4.66(.11)$ & $4.24(.11)^{\mathrm{f}}$ & $6.34(.15)^{\mathrm{c}}$ \\
\hline & Wet $50^{\circ} \mathrm{C}$ & $5.97(.06)$ & $3.53(.13)$ & $5.5(.19)^{\mathrm{d}}$ & $4.19(.09)^{\mathrm{e}}$ & $4.21(.15)^{\mathrm{e}, \mathrm{f}}$ & $5.67(.14)^{\mathrm{d}}$ \\
\hline \multirow{4}{*}{$\begin{array}{l}\text { Young's } \\
\text { modulus E } \\
(G P a)\end{array}$} & $\operatorname{Dry} 21^{\circ} \mathrm{C}$ & $21.71(.14)$ & $13.79(.18)$ & $19.63(.12)$ & $14.25(.15)$ & $14.78(.17)$ & $18.72(.11)$ \\
\hline & Wet $21^{\circ} \mathrm{C}$ & $21.28(.19)$ & $13.01(.22)^{\mathrm{h}}$ & $18.11(.2)^{\mathrm{i}}$ & $13.92(.18)$ & $12.89(.15)^{\mathrm{h}}$ & $17.87(.14)^{\mathrm{i}}$ \\
\hline & Wet $37^{\circ} \mathrm{C}$ & $18.59(.13)$ & $10.67(.16)$ & $17.58(.19)$ & $12.71(.12)^{\mathrm{j}}$ & $12.57(.13)^{\mathrm{j}}$ & 17.09 (.13) \\
\hline & Wet $50^{\circ} \mathrm{C}$ & $15.81(.11)^{\mathrm{g}}$ & $9.7(.21)$ & $15.72(.23)^{\mathrm{g}}$ & $11.51(.13)$ & $11.98(.16)$ & $15.59(.14)^{\mathrm{g}}$ \\
\hline \multirow{4}{*}{$\begin{array}{l}\text { Poisson's } \\
\text { ratio } v\end{array}$} & $\operatorname{Dry} 21^{\circ} \mathrm{C}$ & 0.22 & 0.31 & 0.31 & 0.33 & 0.32 & 0.29 \\
\hline & Wet $21^{\circ} \mathrm{C}$ & 0.26 & 0.34 & 0.36 & 0.34 & 0.41 & 0.34 \\
\hline & Wet $37^{\circ} \mathrm{C}$ & 0.31 & 0.36 & 0.41 & 0.36 & 0.42 & 0.34 \\
\hline & Wet $50^{\circ} \mathrm{C}$ & 0.32 & 0.37 & 0.43 & 0.37 & 0.42 & 0.37 \\
\hline
\end{tabular}

Same superscript letters show values with no statistically significant difference $(p>0.05)$ 
Table 3 Results of dynamic shear modulus $G_{1}$, loss shear modulus $G_{2}$, dynamic viscosity $n^{*}$ and loss tangent under dynamic testing (mean and S.D.)

\begin{tabular}{|c|c|c|c|c|c|c|c|}
\hline & & $\mathrm{CM}$ & EL & $\mathrm{FP}$ & FS & PR & SU \\
\hline \multirow{4}{*}{$\begin{array}{l}\text { Dynamic } \\
\text { shear } \\
\text { modulus } \\
G_{1}(G P a)\end{array}$} & $\operatorname{Dry} 21^{\circ} \mathrm{C}$ & $9.06(.12)$ & $5.6(.09)^{\mathrm{a}}$ & $7.75(.11)^{\mathrm{b}}$ & $5.5(.09)^{\mathrm{a}, \mathrm{d}}$ & $5.57(.13)^{\mathrm{a}}$ & $7.66(.06)^{b}$ \\
\hline & Wet $21^{\circ} \mathrm{C}$ & $8.65(.08)$ & $4.91(.13)$ & $6.61(.1)^{\mathrm{c}}$ & $5.33(.14)^{\mathrm{d}}$ & $4.66(.09)$ & $6.76(.1)^{\mathrm{c}}$ \\
\hline & Wet $37^{\circ} \mathrm{C}$ & $7.84(.13)$ & $4.72(.07)$ & $6.01(.14)$ & $4.96(.11)$ & $4.39(.14)$ & $5.53(.12)$ \\
\hline & Wet $50^{\circ} \mathrm{C}$ & $7.44(.15)$ & $3.87(.18)$ & $5.56(.15)$ & $4.62(.12)$ & $4.12(.16)$ & $5.07(.13)$ \\
\hline \multirow{4}{*}{$\begin{array}{l}\text { Loss shear } \\
\text { modulus } \\
G_{2}(G P a)\end{array}$} & $\operatorname{Dry} 21^{\circ} \mathrm{C}$ & $0.331(.02)$ & $0.142(.03)$ & $0.168(.02)$ & $0.113(.01)$ & $0.188(.02)$ & $0.233(.02)$ \\
\hline & Wet $21^{\circ} \mathrm{C}$ & $0.41(.02)$ & $0.22(.01)$ & $0.355(.01)$ & $0.191(.02)$ & $0.221(.01)$ & $0.332(.02)$ \\
\hline & Wet $37^{\circ} \mathrm{C}$ & $0.454(.04)$ & $0.27(.02)$ & $0.365(.02)$ & $0.2(.02)$ & $0.279(.03)$ & $0.348(.02)$ \\
\hline & Wet $50^{\circ} \mathrm{C}$ & $0.533(.02)$ & $0.308(.02)$ & $0.362(.03)$ & $0.21(.03)$ & $0.301(.03)$ & $0.452(.03)$ \\
\hline \multirow{4}{*}{$\begin{array}{l}\text { Dynamic } \\
\text { viscosity } n^{*} \\
(M P a \cdot s)\end{array}$} & Dry $21^{\circ} \mathrm{C}$ & $22.97(.13)$ & $10.66(.17)^{\mathrm{e}}$ & $13.39(.16)$ & $17.06(.16)^{\mathrm{m}}$ & $10.45(.28)^{\mathrm{e}}$ & $14.09(.34)$ \\
\hline & Wet $21^{\circ} \mathrm{C}$ & $22.31(.12)$ & $10.04(.11)^{\mathrm{f}}$ & $12.73(.23)$ & $16.97(.22)^{\mathrm{m}}$ & $9.74(.23)^{\mathrm{f}, \mathrm{n}}$ & $13.18(.19)$ \\
\hline & Wet $37^{\circ} \mathrm{C}$ & $20.8(.1)$ & $9.74(.08)^{\mathrm{g}, \mathrm{i}}$ & $11.58(.27)^{\mathrm{k}}$ & $16.37(.14)$ & $9.5(.14)^{\mathrm{g}, \mathrm{n}, \mathrm{o}}$ & $11.37(.17)^{\mathrm{k}}$ \\
\hline & Wet $50^{\circ} \mathrm{C}$ & $20.66(.19)$ & $9.53(.18)^{\mathrm{h}, \mathrm{i}}$ & $11.22(.14)^{1}$ & $15.80(.09)$ & $9.32(.18)^{\mathrm{h}, \mathrm{o}}$ & $10.91(.22)^{1}$ \\
\hline \multirow{4}{*}{$\begin{array}{l}\text { Loss } \\
\text { tangent } \\
(\tan \delta)\end{array}$} & $\operatorname{Dry} 21^{\circ} \mathrm{C}$ & $0.034(.002)^{\mathrm{p}}$ & $0.027(.001)$ & $0.022(.002)^{\mathrm{u}}$ & $0.021(.001)^{\mathrm{u}}$ & $0.032(.002)^{\mathrm{p}}$ & $0.031(.002)^{p}$ \\
\hline & Wet $21^{\circ} \mathrm{C}$ & $0.043(.002)^{\mathrm{q}}$ & $0.042(.002)^{\mathrm{q}}$ & $0.043(.002)^{\mathrm{q}}$ & $0.035(.001)^{\mathrm{v}}$ & $0.038(.002)^{\mathrm{v}}$ & $0.047(.002)$ \\
\hline & Wet $37^{\circ} \mathrm{C}$ & $0.054(.002)^{\mathrm{r}}$ & $0.059(.002)$ & $0.047(.003)$ & $0.04(.002)$ & $0.052(.001)^{\mathrm{r}}$ & $0.055(.003)^{r}$ \\
\hline & Wet $50^{\circ} \mathrm{C}$ & $0.070(.003)$ & $0.078(.003)^{\mathrm{s}}$ & $0.055(.003)$ & $0.045(.002)$ & $0.062(.002)$ & $0.078(.003)^{\mathrm{s}}$ \\
\hline
\end{tabular}

Same superscript letters show values with no statistically significant difference $(p>0.05)$

Table 4 Creep results of initial strain $\gamma_{0}$, \% residual strain of initial $\gamma_{t} / \gamma_{0}$, \% recovery after 3 hrs and initial shear modulus (mean and S.D.)

\begin{tabular}{|c|c|c|c|c|c|c|}
\hline Materials & $\begin{array}{l}\text { Applied torque } \\
\left(\mathrm{Nm} / \mathrm{A} \times 10^{-4}\right)\end{array}$ & $\begin{array}{c}\text { Initial stress } \\
(\mathrm{MPa})\end{array}$ & $\begin{array}{l}\text { Initial strain } y_{0} \\
\quad\left(\mathrm{rad} \times 10^{-4}\right)\end{array}$ & $\begin{array}{c}\text { \% residual } \\
\text { strain of initial } \\
\left(\gamma_{\mathrm{t}} / \gamma_{0}\right)\end{array}$ & $\begin{array}{l}\text { \% Recovery } \\
\text { after } 3 \text { hrs of } \\
\text { creep }\end{array}$ & $\begin{array}{c}\text { Initial shear } \\
\text { modulus at } 10 \mathrm{~s} \\
(\mathrm{GPa})\end{array}$ \\
\hline \multirow{6}{*}{$\mathrm{CM}$} & 1.37 & 1.14 & - & - & - & \multirow{6}{*}{$8.77(0.22)^{\mathrm{g}}$} \\
\hline & 2.06 & 1.71 & - & - & - & \\
\hline & 2.75 & 2.28 & $1.18(.16)$ & 0 & 100 & \\
\hline & 4.12 & 3.42 & $1.84(.13)$ & 0 & 100 & \\
\hline & 5.5 & 4.56 & $2.3(.19)$ & $4.42(.21)$ & $96.73(.29)$ & \\
\hline & 6.87 & 5.7 & $2.88(.17)$ & $4.86(.32)$ & $96.25(.23)$ & \\
\hline \multirow{4}{*}{ EL } & 1.37 & 1.14 & $1.95(.08)^{\mathrm{a}}$ & 0 & $100^{\mathrm{e}}$ & \multirow{4}{*}{$5.51(0.12)^{\mathrm{h}}$} \\
\hline & 2.06 & 1.71 & $3.15(.14)^{\mathrm{b}, \mathrm{d}}$ & $7.49(.28)$ & $96.24(.13)$ & \\
\hline & 2.75 & 2.28 & $4.18(.15)^{\mathrm{c}}$ & $11.31(.33)$ & $93.71(.19)$ & \\
\hline & 4.12 & 3.42 & $6.21(.11)^{\mathrm{d}}$ & $11.93(.14)$ & $92.18(.15)$ & \\
\hline \multirow{4}{*}{$\mathrm{FP}$} & 1.37 & 1.14 & $1.29(.2)$ & $2.48(.2)$ & $98.56(.21)$ & \multirow{4}{*}{$8.44(0.38)^{\mathrm{g}}$} \\
\hline & 2.06 & 1.71 & $2.01(.23)$ & $4.06(.26)$ & $97.53(.28)$ & \\
\hline & 2.75 & 2.28 & $2.71(.19)$ & $6.38(.25)$ & $96.36(.3)$ & \\
\hline & 4.12 & 3.42 & $4.26(.22)$ & $9.43(.32)$ & $95.01(.22)^{\mathrm{f}}$ & \\
\hline \multirow{4}{*}{ FS } & 1.37 & 1.14 & $2.25(.16)$ & 0 & $100^{\mathrm{e}}$ & \multirow{4}{*}{$5.4(0.25)^{\mathrm{h}}$} \\
\hline & 2.06 & 1.71 & $3.24(.12)^{\mathrm{d}}$ & $2.94(.13)$ & $98.52(.17)$ & \\
\hline & 2.75 & 2.28 & $4.18(.14)^{\mathrm{c}}$ & $3.39(.24)$ & $97.75(.16)$ & \\
\hline & 4.12 & 3.42 & $5.61(.17)$ & $3.93(.19)$ & $96.91(.21)$ & \\
\hline \multirow{4}{*}{ PR } & 1.37 & 1.14 & $1.97(.07)^{\mathrm{a}}$ & $8.02(.17)$ & $95.02(.19)$ & \multirow{4}{*}{$5.65(0.18)^{\mathrm{h}}$} \\
\hline & 2.06 & 1.71 & $2.99(.15)^{b}$ & $9.42(.19)$ & $94.39(.23)$ & \\
\hline & 2.75 & 2.28 & $3.95(.1)^{\mathrm{c}}$ & $12.34(.22)$ & $93.15(.15)$ & \\
\hline & 4.12 & 3.42 & $6.38(.11)^{\mathrm{d}}$ & $15.14(.24)$ & $91.81(.18)$ & \\
\hline \multirow{6}{*}{$\mathrm{SU}$} & 1.37 & 1.14 & - & - & - & \multirow{6}{*}{$7.18(0.47)$} \\
\hline & 2.06 & 1.71 & - & - & - & \\
\hline & 2.75 & 2.28 & $3.47(.23)$ & $7.5(.14)$ & $95.8(.22)$ & \\
\hline & 4.12 & 3.42 & $4.84(.18)$ & $8.28(.25)$ & $95.06(.19)^{\mathrm{f}}$ & \\
\hline & 5.5 & 4.56 & $5.99(.24)$ & $9.19(.28)$ & $94.55(.32)$ & \\
\hline & 6.87 & 5.7 & $7.65(.25)$ & $9.73(.19)$ & $94.87(.27)$ & \\
\hline
\end{tabular}

Same superscript letters show values with no statistically significant difference $(p>0.05)$ 


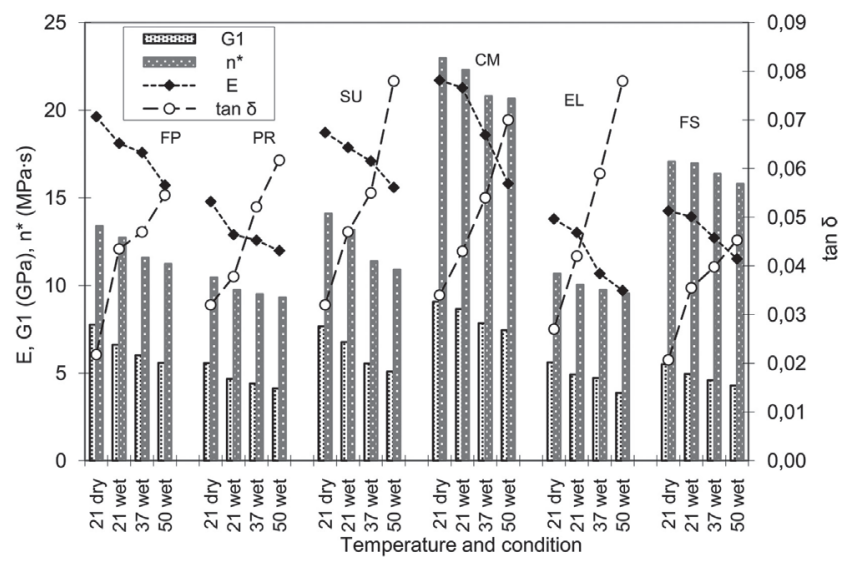

Fig. 2 Effect of temperature and condition on $G_{1}, n^{*}, E$, $\tan \delta$.

(a)

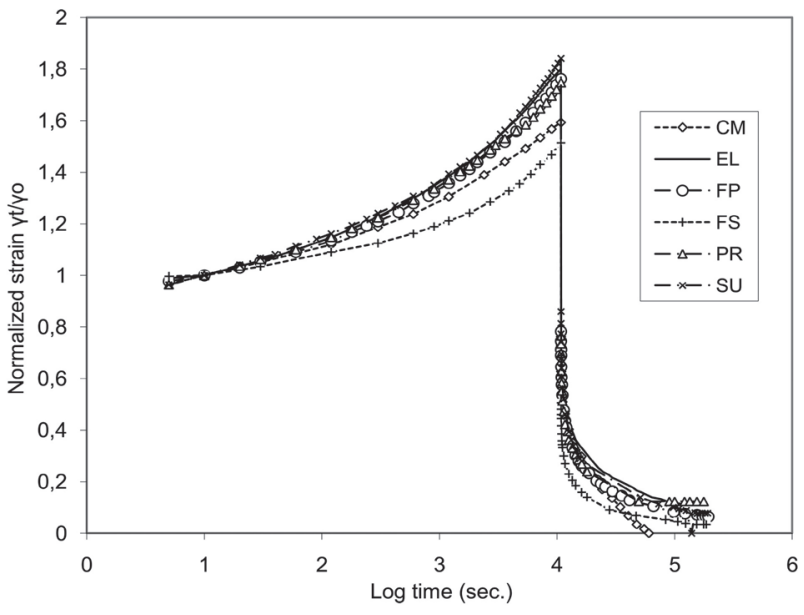

elastic and viscoelastic. Material CM showed initial strain too small to accurately measure at the two lowest stresses used and also showed the least initial strain. It recovered fully at $2.75 \mathrm{MPa}$ and $4.12 \mathrm{MPa}$ stresses. SU also showed initial strain too small to accurately measure at the lowest stresses. It did not recover fully at higher stresses. Among the other materials EL and FS did not exhibit residual strain under the lowest stress employed.

\section{DISCUSSION}

Viscoelastic properties are crucial for the longevity of composite resin restorations and affect their performance in different ways. On one hand, materials with low moduli are unable to withstand the forces generated inside the oral cavity and are more prone to wear ${ }^{9)}$, while presenting lower fracture toughness ${ }^{10)}$. On the other

(b)

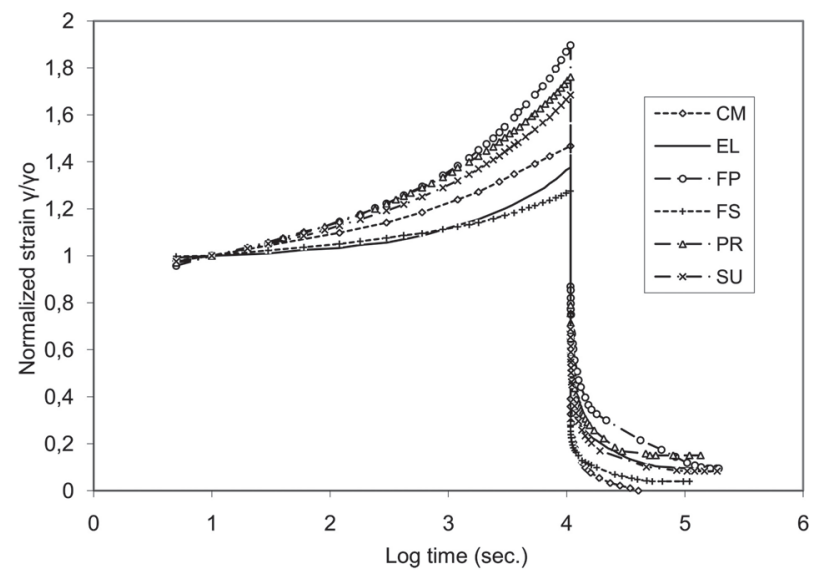

Fig. 3 Creep and recovery curves of the materials:a) applied torque of $2.75 \times 10^{-4} \mathrm{Nm} / \mathrm{A}$, b) applied torque of $4.12 \times 10^{-4} \mathrm{Nm} / \mathrm{A}$.

(a)

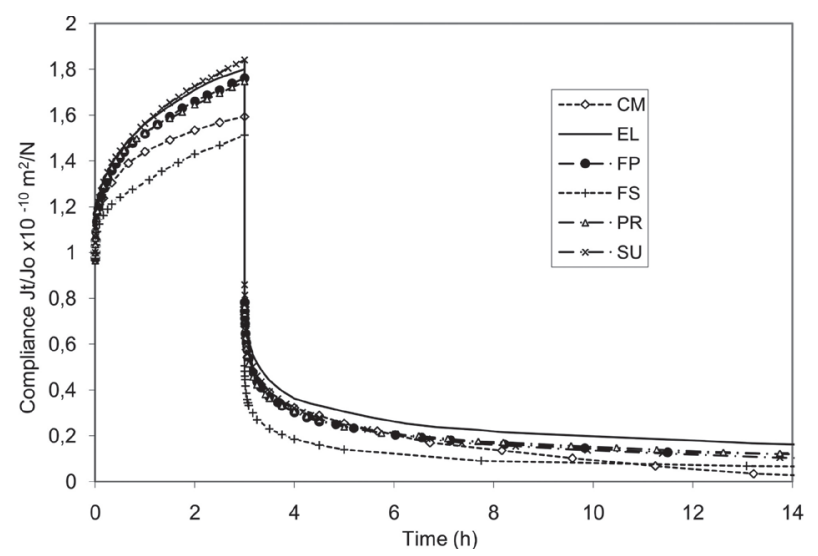

(b)

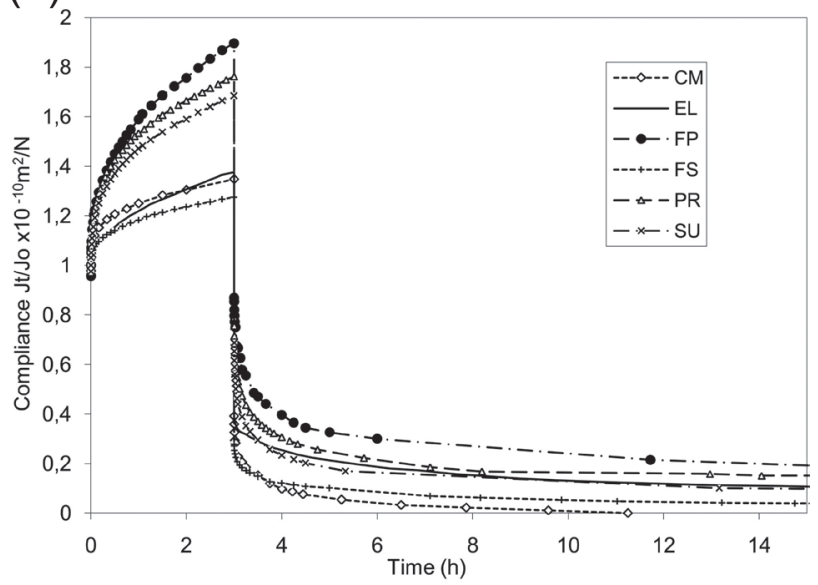

Fig. 4 Creep compliance curves of the materials:a) applied torque of $2.75 \times 10^{-4} \mathrm{Nm} / \mathrm{A}$, b) applied torque of $4.12 \times 10^{-4} \mathrm{Nm} / \mathrm{A}$. 
hand, composites that are too stiff may transmit occlusal stresses to tooth structure resulting in catastrophic failure, while in cervical restorations less viscous and less stiff materials as layers have been proposed ${ }^{11}$. Moreover, elastic modulus is also important during polymerization shrinkage ${ }^{12)}$. Composites with higher moduli have been associated with higher shrinkage stresses $^{13)}$ as they are not able to relieve them with plastic flow during polymerization. Thus, composites are required to have satisfactory stiffness in order to possess sufficient mechanical properties, but not to be too stiff in order to minimize setting stresses.

The ideal value of a composite resin's Young's modulus has been set to $18 \mathrm{GPa}$ which is the value of dentin $^{14,15)}$, in order to achieve a better stress distribution between restoration and tooth. In the nearest conditions to those inside the oral cavity $\left(37^{\circ} \mathrm{C}\right.$ and wet) $\mathrm{CM}, \mathrm{FP}$ and SU were very near this value, while EL, FS and PR presented significantly lower values. However with the increase of temperature, $E$ decreased and at $50^{\circ} \mathrm{C}$ the materials showed values ranging from $9.7 \mathrm{GPa}$ to 15.81 GPa. Although temperature changes are small most of the time, consumption of very hot or cold foods or beverages can result in variations meaning that under these conditions restorations could be more prone to failure in stress-bearing cavities.

The Poisson's ratio of all the materials was of reasonable magnitude. Poisson's ratio is the ratio of transverse contraction strain to the longitudinal extension strain, a measure of the relative resistance to dilatation and shearing. For glassy polymers Poisson's ratio is between 0.3 and 0.35 . A Poisson's ratio approaching 0.5 corresponds to a rubbery consistency. As a result of its high filler content CM had the lowest Poisson's ratio among the materials. The value 0.22 for $\mathrm{CM}$ in the dry condition suggests the ceramic particle inclusions have a substantial effect. Poisson's ratios exceeding 0.4 were inferred for FP and PR materials when wet at $50^{\circ} \mathrm{C}$, indicating substantial softening of the shear modulus in comparison with the bulk modulus.

In the present study, three novel composites resins were tested and compared to conventional packable composites. Each of the low-shrinking composites employs a different strategy in order to achieve this goal and consequently the materials differed among them. CM has very high filler content (82 vol\%) which reduces the amount of available resin matrix in the resin composite and leads to lower volumetric shrinkage ${ }^{16,17)}$. Its high filler content explains the high moduli values that were obtained, which is probably the reason for its high wear resistance found in one study ${ }^{18}$ ) and possibly other mechanical properties. However, despite its low shrinkage this material was found to show similar marginal adaptation to materials that shrink more ${ }^{19}$. This phenomenon was attributed to other factors that influence the adaptation of composites, namely stiffness and viscosity, which is affirmed from the current findings. Apart from its high moduli, CM presented high viscosity $(>20 \mathrm{MPa} \cdot \mathrm{s}$ under all conditions) which means that it is less able to compensate stresses with viscous flow both during setting and later under masticatory forces. As a result of its high filler content, $\mathrm{CM}$ had the lowest Poisson's ratio among the materials, which is the ratio of transverse contraction strain to the longitudinal extension strain, a measure of the relative resistance to dilatation and shearing. The manufacturers of CM claim that it possesses low water sorption and under the $24 \mathrm{~h}$ water storage of this study it seems to be valid, as CM presented satisfactory stability in its properties when tested dry and wet at $21^{\circ} \mathrm{C}$. A possible reason is that the plasticizing effect of water which creates more free volume and facilitates the polymer chain segment movement is hindered by the material's high filler content and limited monomer volume and possibly also by the new filler surface coating used in CM. Contrarily, the increase of temperature had a significant effect on the properties of CM, especially on $G$ and $E$ which exhibited the largest decrease among the materials tested.

In the case of EL, the absence of the diluent monomer TEGDMA is possibly the reason this material has been found to possess a relatively low degree of cure (\%DC) in the early stages of polymerization ${ }^{19)}$ which is associated with a decreased polymerization shrinkage strain ${ }^{20)}$. However, a low \%DC can have a detrimental effect on the mechanical properties of a composite resin. In the present study EL was found to possess the lowest moduli among the materials tested and also the highest loss tangent when tested wet in $37^{\circ} \mathrm{C}$ and $50^{\circ} \mathrm{C}$. Loss tangent is the ratio of the energy lost to the stored energy in a cyclic deformation and a low value along with a relatively high modulus contribute positively to the clinical performance concerning deformation ${ }^{21)}$.

Lastly, FS is a material consisting of a new monomer technology that uses a combination of a siloxane backbone along with oxirane molecules and a cationic ring opening polymerization process resulting in a polysilorane polymer. Among the materials tested it was the only one based on a different monomer technology. This material showed a relatively low shear and flexural modulus. However, in all testing conditions it had the lowest loss tangent and it was the material which was affected the least by water at $21^{\circ} \mathrm{C}$ exhibiting no change or the smallest changes when stored in water for $24 \mathrm{~h}$. This stability is attributed to its monomer chemistry. The siloxane backbone of silorane is highly hydrophobic thus making the reactive to water oxirane groups inaccessible to water molecules ${ }^{22)}$.

Packable composite resins were manufactured in order to provide composites with handling properties similar to amalgam and improved mechanical properties compared to other composites ${ }^{23)}$. However, variations amidst the materials of this category are significant as found both in previous studies ${ }^{24}$ and the present one. Among the packable composites tested FP showed the highest moduli and PR the lowest, in accordance with previous findings ${ }^{21)}$. FP had the second highest filler content and a high proportion of finer fillers providing a stiffer consistency. On the other hand, PR apart from its lower moduli exhibited the largest variations when 
stored wet and when the temperature increased.

When tested under creep the composites were characterized by a rapid initial strain which was followed by retarded strain. The initial strain and the \% residual strain increased with the increase of applied torque. CM and SU exhibited negligible strain under the two lowest torques employed. Moreover, CM was the only material to exhibit full recovery in the two highest torques used. Creep has been found to be influenced by filler content ${ }^{25}$ ) and an inverse relationship between creep compliance and filler loading was shown ${ }^{26}$ ) explaining the behavior of this heavily-filled material.

FS was proved to be the least susceptible material to creep, surpassing CM when the applied stress increased. As FS possesses the lowest filler content, the reason for its high creep resistance should be attributed to other factors possibly to its monomer composition ${ }^{26)}$ or filler coupling. On the other hand, SU showed negligible strains under the lowest strains and this creep resistance was previously attributed to its monomer chemistry which contains $\mathrm{UDMA}^{27)}$. However, SU showed high susceptibility to creep when the torque increased, a finding that the authors cannot explain. PR was not able to fully recover and exhibited both the lowest recovery and the highest \% of residual strain of its initial strain at 10s. Creep resistance is important for polymers as high strains make the material more prone to mechanical stresses, but it should be noted that while excessive creep is unwanted an optimized level of compliance may delay catastrophic failure and wear ${ }^{28)}$.

While in parameters as elastic moduli, loss tangent and Poisson's ratio there was no consistent behavior among the two groups of materials, in creep testing the "conventional" packable materials were more prone to creep and exhibited higher compliance than the lowshrinking composites. It is however difficult to explain this finding because of the compositional differences among all the materials. It is nonetheless confirmed by our findings that while filler content plays an important role other factors are greatly involved in the creep resistance of composite resins. While the highly filled material CM showed good creep results, materials EL and FS with similar or lower filler volume than packable composites exhibited better performance than those.

\section{CONCLUSIONS}

Six novel dental composites were studied for viscoelastic behavior. CM presented the highest shear and flexural modulus and EL the lowest. All materials softened by an increase of temperature. FS was the least affected by water and PR showed to be the most susceptible to softening by hydration.

The various strategies employed in order to lower polymerization shrinkage result in materials with different chemistry and mechanical properties. While it is important to have materials with low shrinkage values, this should be achieved without risking the mechanical behavior of the composite resins, especially when dealing with posterior restorations.

\section{REFERENCES}

1) Ruyter IE. Composites - characterization of composite filling materials: reactor response. Adv Dent Res 1988; 2: 122-129; discussion 129-133.

2) Lohbauer U, Frankenberger R, Kramer N, Petschelt A. Strength and fatigue performance versus filler fraction of different types of direct dental restoratives. J Biomed Mater Res B Appl Biomater 2006; 76: 114-120.

3) Ferracane JL. Developing a more complete understanding of stresses produced in dental composites during polymerization. Dent Mater 2005; 21: 36-42.

4) Suliman AA, Boyer DB, Lakes RS. Cusp movement in premolars resulting from composite polymerization shrinkage. Dent Mater 1993; 9: 6-10.

5) Ilie N, Hickel R. Silorane-based dental composite: behavior and abilities. Dent Mater J 2006; 25: 445-454.

6) Ilie N, Jelen E, Clementino-Luedemann T, Hickel R. Lowshrinkage composite for dental application. Dent Mater J 2007; 26: 149-155.

7) Papadogiannis DY, Lakes RS, Papadogiannis Y, Palaghias G, Helvatjoglu-Antoniades M. The effect of temperature on the viscoelastic properties of nano-hybrid composites. Dent Mater 2008; 24: 257-266.

8) Papadogiannis D, Lakes RS, Palaghias G, Papadogiannis Y. Creep and dynamic viscoelastic behavior of endodontic fiberreinforced composite posts. J Prosthodont Res 2009; 53: 185-192.

9) Condon JR, Ferracane JL. In vitro wear of composite with varied cure, filler level, and filler treatment. J Dent Res 1997; 76: 1405-1411.

10) Ferracane JL, Berge HX. Fracture toughness of experimental dental composites aged in ethanol. J Dent Res 1995; 74: 1418-1423.

11) Senawongse P, Pongprueksa P, Tagami J. The effect of the elastic modulus of low-viscosity resins on the microleakage of Class $\mathrm{V}$ resin composite restorations under occlusal loading. Dent Mater J 2010; 29: 324-329.

12) Braga RR, Ballester RY, Ferracane JL. Factors involved in the development of polymerization shrinkage stress in resincomposites: a systematic review. Dent Mater 2005; 21: 962-970.

13) Condon JR, Ferracane JL. Assessing the effect of composite formulation on polymerization stress. J Am Dent Assoc 2000; 131: 497-503.

14) Willems G, Lambrechts P, Braem M, Celis JP, Vanherle G. A classification of dental composites according to their morphological and mechanical characteristics. Dent Mater 1992; 8: 310-319.

15) Abe $Y$, Lambrechts $P$, Inoue $S$, Braem MJ, Takeuchi M, Vanherle G, Van Meerbeek B. Dynamic elastic modulus of 'packable' composites. Dent Mater 2001; 17: 520-525.

16) Kleverlaan CJ, Feilzer AJ. Polymerization shrinkage and contraction stress of dental resin composites. Dent Mater 2005; 21: 1150-1157.

17) Labella R, Lambrechts P, Van Meerbeek B, Vanherle G. Polymerization shrinkage and elasticity of flowable composites and filled adhesives. Dent Mater 1999; 15: 128-137.

18) Topcu FT, Erdemir U, Sahinkesen G, Yildiz E, Uslan I, Acikel C. Evaluation of microhardness, surface roughness, and wear behavior of different types of resin composites polymerized with two different light sources. J Biomed Mater Res B Appl Biomater 2010; 92: 470-478.

19) Papadogiannis D, Kakaboura A, Palaghias G, Eliades G. Setting characteristics and cavity adaptation of low-shrinking resin composites. Dent Mater 2009; 25: 1509-1516.

20) Silikas N, Eliades G, Watts DC. Light intensity effects on resin-composite degree of conversion and shrinkage strain. 
Dent Mater 2000; 16: 292-296.

21) Papadogiannis Y, Helvatjoglu-Antoniades M, Lakes RS. Dynamic mechanical analysis of viscoelastic functions in packable composite resins measured by torsional resonance. J Biomed Mater Res B Appl Biomater 2004; 71: 327-335.

22) Eick JD, Smith RE, Pinzino CS, Kostoryz EL. Stability of silorane dental monomers in aqueous systems. J Dent 2006; 34: 405-410.

23) Ilie N, Hickel R. Investigations on mechanical behaviour of dental composites. Clin Oral Invest 2009; 13: 427-438.

24) Papadogiannis Y, Lakes RS, Palaghias G, HelvatjogluAntoniades M, Papadogiannis D. Fatigue of packable dental composites. Dent Mater 2007; 23: 235-242.
25) Vaidyanathan J, Vaidyanathan TK. Flexural creep deformation and recovery in dental composites. J Dent 2001; 29: 545-551.

26) Baroudi K, Silikas N, Watts DC. Time-dependent viscoelastic creep and recovery of flowable composites. Eur J Oral Sci 2007; 115: 517-521.

27) Marghalani HY, Al-Jabab AS. Compressive creep and recovery of light-cured packable composite resins. Dent Mater 2004; 20: 600-610.

28) Vaidyanathan TK, Vaidyanathan J, Cherian Z. Extended creep behavior of dental composites using time-temperature superposition principle. Dent Mater 2003; 19: 46-53. 